\title{
Assessment of genetic diversity in bread wheat (Triticum aestivum L.) using RAPD markers
}

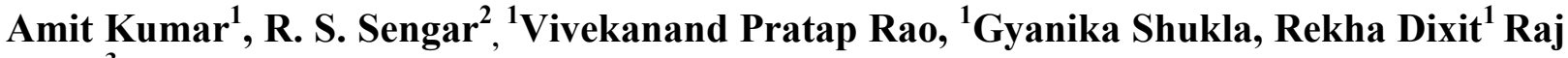 \\ Singh $^{3}$ \\ ${ }^{1}$ Department of Biotechnology, Faculty of Science, Swami Vivekanand Subharti University, Meerut-250005 (UP), \\ INDIA \\ ${ }^{2}$ Department of Agriculture Biotechnology, Sardar Vallabhbhai Patel University of Agriculture and Technolo- \\ gyMeerut-250110(U.P), INDIA \\ ${ }^{3}$ Department of Botany, Faculty of science, Swami Vivekanand Subharti University, Meerut-250005 (UP), INDIA \\ *Corresponding author. E-mail: amit.agbiotech1581@gmail.com
}

Received: November 11, 2016; Revised received: March 30, 2017; Accepted: August 20, 2017

Abstract: The present study aimed to evaluate the genetic diversity of 10 wheat cultivars by Random Amplified Polymorphic DNA (RAPD) marker. The genomic DNA of 10 wheat genotypes were amplified with 10 RAPD primers that produced 53 amplified band, out of which 23 band were polymorphic (43.39\%). The number of fragment amplified per primer ranged from 4 to 9 . Primer A01 generated maximum number of amplified band, out of which 5 band were polymorphic. Cluster analysis of wheat genotypes were based on UPGMA method. Cluster analysis of 10 wheat genotypes were classified in to two main group; single variety AKW 1071 was placed in first group and rest 9 variety were placed in second group. The pair wise similarity values ranged from $0.58 \%$ to $100 \%$ and showed that cultivars Raj-3765 and K-7903 were the closest with highest similarity value (100\%), while genotypes AKW 1071 and K9006 showed minimum similarity value (62\%). The present study indicated the presence of high genetic diversity among wheat cultivars, which could be used for the developing core collection of wheat germplasm for breeding purpose.

Keywords: Cluster analysis, RAPD marker, UPGMA method, Wheat genotypes

\section{INTRODUCTION}

Wheat is a major staple food in all over the world. Wheat production in India has a crucial role in Agriculture. The overall production of wheat in India in 2013-14 was $95.6 \mathrm{mt}$. In the past few decade morphological characters were using for the characterization of germplasm. Such characters are limited in number and show growth stage and environment dependent expression. From the last few decade isozymes were using for the study of genetic diversity (Hemrick and Godt., 1990).In Recent year molecular marker are being used for the assessment of genetic diversity and identification of crop genotype (Tar'an et al., 2005, Sunil kumar et al., 2016). Most of the molecular markers such as RAPD (Random Amplified Polymorphic DNA), SSR (Simple Sequence Repeat), AFLP (Amplified Fragment Length Polymorphism) and ISSR (Inter Simple Sequence Repeat) have been used for the assessment of genetic diversity. Among several molecular marker RAPD is mostly use for the assessment of genetic diversity in several important agronomic crops (Mahpara et al., 2012). RAPD could be easily used for the screening of breeding population at large scale (Demekeet et al., 1996). It has been successfully used for the assessment of genetic diversity of diploid, tetraploid and hexaploid wheat (Sivolap et al., 1999). The wheat genotypes were grown at the pots of the Swami Vivekanand Subharti University, Meerut. The investigation of wheat cultivars by RAPD primers were used to evaluate individual genotype (Ali Ammar et al., 2013, Kumar et al., 2015). The aim of this study was to assess genetic diversity of ten Indian wheat cultivars using RAPD marker.

\section{MATERIALS AND METHODS}

Plant material: Seeds of ten selected wheat genotypes (Table-1) were collected from Sardar Vallabhbhai Patel University of Agriculture and Technology, Meerut. DNA extraction and RAPD genotyping: CTAB (Cetyltrimethylammonium bromide) method was used for the extraction of DNA from the leaves of the plant, which is modified method of Doyle and Doyle (1987). The leaves of wheat plants were collected and crushed in liquid nitrogen. After collecting the crushed powder of leaves in eppendrof tubes, 500 micro liter of CTAB buffer was added in to each eppendrof tubes. Composition of CTAB buffer was $1.4 \mathrm{M} \mathrm{NaCl}, 100 \mathrm{mM}$ Tris, $20 \mathrm{mM}$ EDTA and $2 \% \mathrm{CTAB}$. The mixture of leaf 
tissue and CTAB buffer were incubated for 1 hour at $60^{\circ} \mathrm{C}$. After one hour of incubation equal volume (500 $\mu \mathrm{l})$ of chloroform and Isoamyl alcohol ratio (24.1) was added and shaken until a homogenous mixture was obtained. Samples were centrifuged at $10000 \mathrm{rpm}$ for 10 minute in bench centrifuge. The supernatant were transferred into fresh eppendrof and cold isopropanol $(250 \mu \mathrm{l})$ were added in eppendrof and mixed gently to precipitate the DNA at $-20^{\circ} \mathrm{C}$ for overnight. Thereafter samples were centrifuged at $10000 \mathrm{rpm}$ for 10 minute and pellet was deposited at the bottom of eppendrof was recovered after supernatant removal from the samples. After removing the supernatant, the pellet was washed with $70 \%$ ethanol and dried at room temperature for 30 minute. Thereafter pellet was dissolved in $50 \mu \mathrm{l}$ of TE buffer and stored at $4^{\circ} \mathrm{C}$ until used. Ten RAPD primers are used for the amplification of DNA. The sequence and code of RAPD primer were given in Table-1. The reaction mixture for RAPD genotyping

Table 1. List of Ten Wheat cultivars with their pedigree.

\begin{tabular}{lll}
\hline S. N. & Variety & Pedigree \\
\hline 1 & AKW 1071 & VEE'S'/ 3FLN/ACC// ANA \\
2 & K 9006 & CPAN 1687/HD 2204 \\
3 & K 0307 & K 8321/UP 2003 \\
4 & K 7903 & HD 1982/K816 \\
5 & RAJ 3765 & HD 2402/VL639 \\
6 & LOK 1 & S308 / S331 \\
7 & V1 & BL 1724/BL1887//BL2031 \\
8 & V2 & BL 1724/BL1887//BL2031 \\
9 & V3 & BL 1724/BL1887//BL2031 \\
10 & K 65 & C591/NP773 \\
\hline
\end{tabular}

was carried out as the follows, in $25 \mu \mathrm{l}$ reaction mixture contained $.75 \mathrm{ng}$ DNA, $0.2 \mathrm{mM}$ of each dNTP, $20 \mathrm{pM}$ primer and one unit Taq polymerase were used per amplification. Thermal PCR was used for the amplification of DNA. The PCR program for the amplification was: initial denaturation at $94^{\circ} \mathrm{C}$ for 5 minute, 40 cycles of $94^{\circ} \mathrm{C}$ for 1 minute, $35^{\circ} \mathrm{C}$ of annealing for 2 minute and finally extension at $72^{\circ} \mathrm{C}$ for 5 minute. After PCR amplification products were separated at $1.5 \%$ agarose gel in $1 \mathrm{X}$ TAE buffer at $50 \mathrm{~V}$ constant voltage for one hour. Gels were stained with ethidium bromide and images were obtained by molecular analyst program of Bio-Rad. A $100 \mathrm{bp}$ ladder used for analysis of amplified band. Data were recorded as presence (1) or absence ( 0$)$ of each amplification band, to construct the band matrix.

The Similarity coefficient of 10 wheat cultivars was calculated according to Nei and Lis (1979). The similarity matrix (Table-3) calculated using jaccard's coefficient (Jaccard, 1908) and dendogram (Fig-1) obtained by clustering according to UPGMA (Unweighted Pair Group Method with Arithmetic average).

\section{RESULTS AND DISCUSSION}

In the study 10 RAPD primers (Table-2) were used for the genetic diversity of 10 wheat cultivars. In the wheat genotypes 23 bands showed polymorphism out of 53 amplified bands. Primer A01and A16 displayed (Fig. 4) high number of Amplified bands while minimum numbers of amplified bands were detected in B-

Table 2. Primer Sequence, percent of GC content and \% of polymorphism of selected RAPD Primer.

\begin{tabular}{llllll}
\hline RAPD Primer & Sequence & GC\% & Amplified Band & Polymorphic Band & \% of Polymorphic Band \\
\hline A01 & 5' CAG GCC CTT C 3' & $70 \%$ & 9 & 5 & $55 \%$ \\
A16 & 5' AGC CAG CGA A 3' & $50 \%$ & 7 & 1 & $14.28 \%$ \\
A20 & 5' GTT GCG ATC C 3' & $60 \%$ & 5 & 3 & $60 \%$ \\
B18 & 5' CCA CAG CAG T 3' & $60 \%$ & 5 & 3 & $60 \%$ \\
B19 & 5' ACC CCC GAA G 3' & $70 \%$ & 4 & 1 & $25 \%$ \\
C13 & 5' AAG CCT CGT C 3' & $60 \%$ & 5 & 2 & $40 \%$ \\
OPA03 & 5'-CAG GCC TGA C-3 & $70 \%$ & 4 & 2 & $50 \%$ \\
OPA04 & 5'AAT CGG GCT G3' & $60 \%$ & 5 & 2 & $40 \%$ \\
OPA07 & 5'GAA ACG GGT G3 & $60 \%$ & 5 & 2 & $40 \%$ \\
OPA08 & 5'GTG ACG TAG G3 & $60 \%$ & 4 & 2 & $50 \%$ \\
& & Total & 53 & 23 & \\
\hline
\end{tabular}

Table 3. Similarity matrix showing the relationship among the 10 wheat genotypes based on RAPD data.

\begin{tabular}{|c|c|c|c|c|c|c|c|c|c|c|}
\hline Genotypes & AKW1071 & K9006 & LOK1 & V3 & RAJ3765 & K0307 & V1 & $\mathrm{V} 2$ & K7903 & K65 \\
\hline AKW1071 & 1.00 & & & & & & & & & \\
\hline K9006 & 0.43 & 1.00 & & & & & & & & \\
\hline LOK1 & 0.56 & 0.87 & 1.00 & & & & & & & \\
\hline V3 & 0.60 & 0.81 & 0.93 & 1.00 & & & & & & \\
\hline RAJ3765 & 0.60 & 0.70 & 0.82 & 0.76 & 1.00 & & & & & \\
\hline K0307 & 0.58 & 0.60 & 0.52 & 0.56 & 0.66 & 1.00 & & & & \\
\hline V1 & 0.53 & 0.56 & 0.58 & 0.62 & 0.73 & 0.75 & 1.00 & & & \\
\hline V2 & 0.61 & 0.62 & 0.75 & 0.68 & 0.80 & 0.57 & 0.64 & 1.00 & & \\
\hline K7903 & 0.60 & 0.70 & 0.82 & 0.76 & 1.00 & 0.66 & 0.73 & 0.80 & 1.00 & \\
\hline K65 & 0.69 & 0.58 & 0.70 & 0.64 & 0.86 & 0.76 & 0.71 & 0.78 & 0.86 & 1.00 \\
\hline
\end{tabular}


Amit Kumar et al. / J. Appl. \& Nat. Sci. 9 (3): 1751 -1755 (2017)

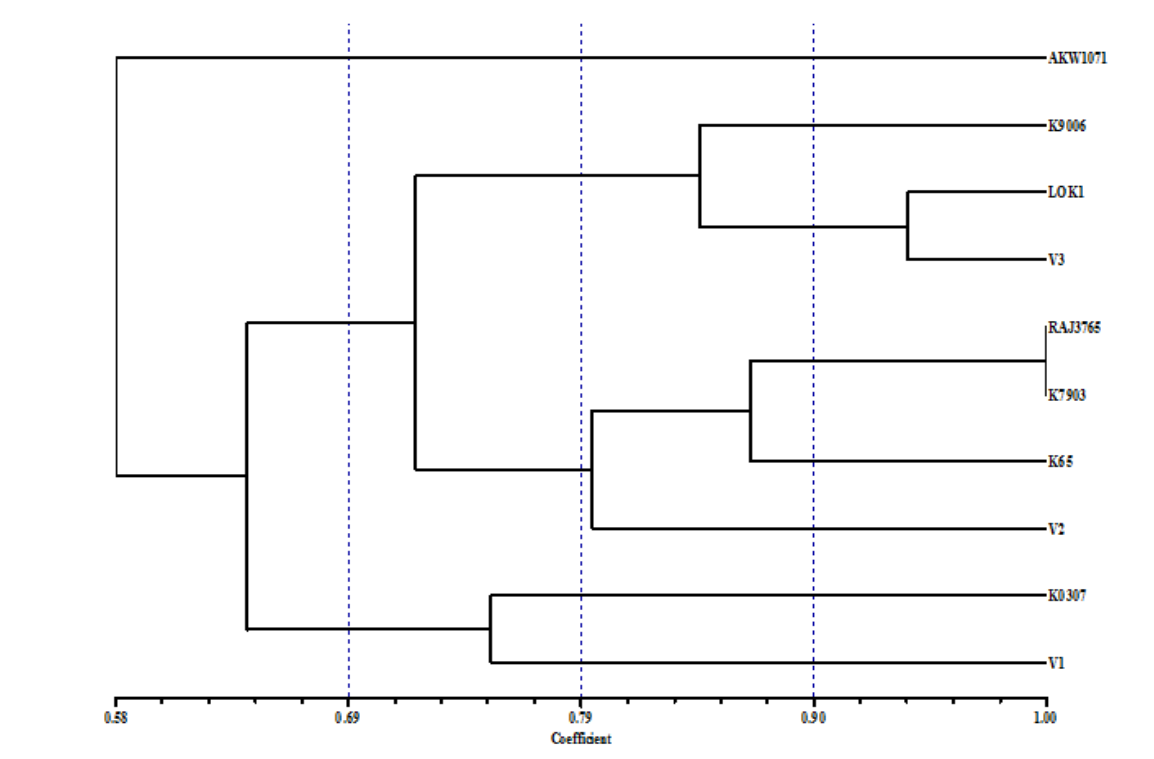

Fig. 1. Dendrogram Illustrating genetic relationships among 10 wheat cultivars, Generated by using UPGMA based on jaccard's coefficient.

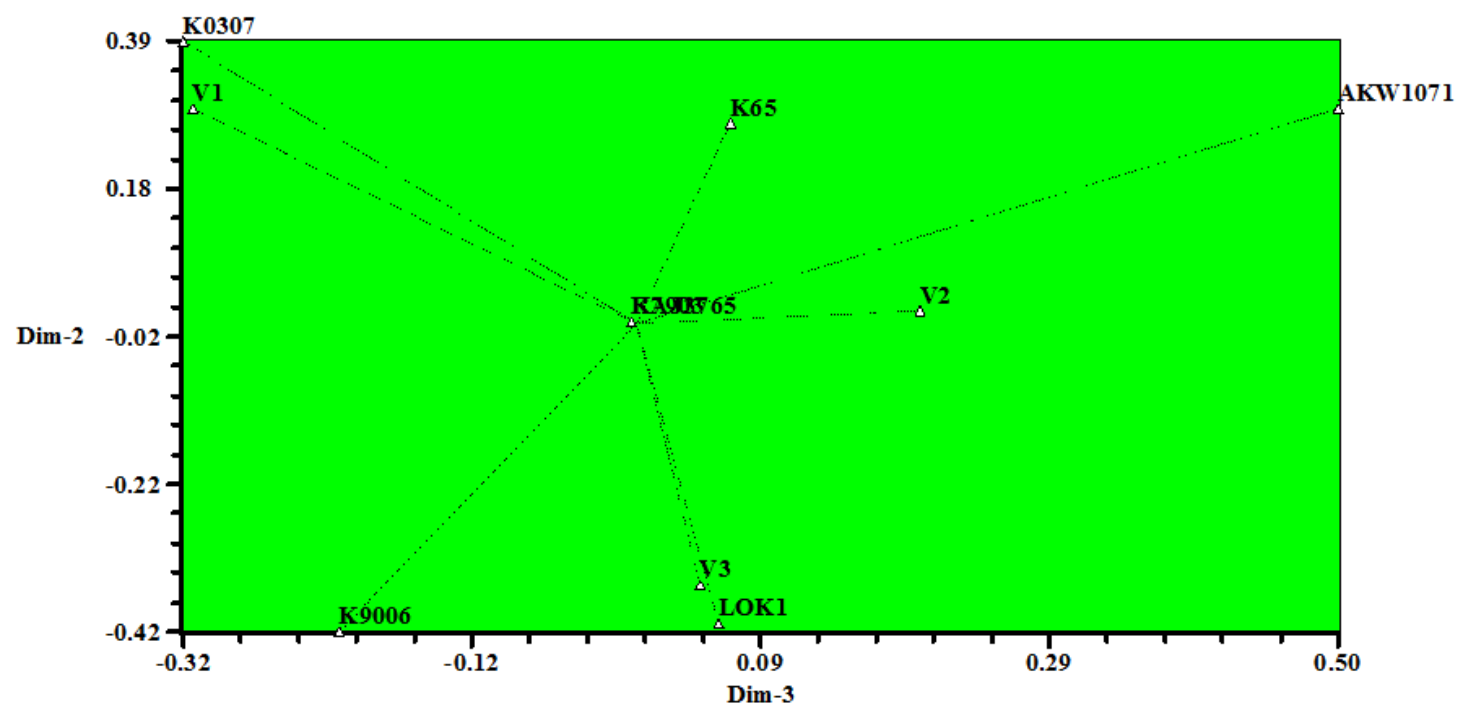

Fig. 2. Two-Dimensional structure of cultivars examined based on RAPD data.

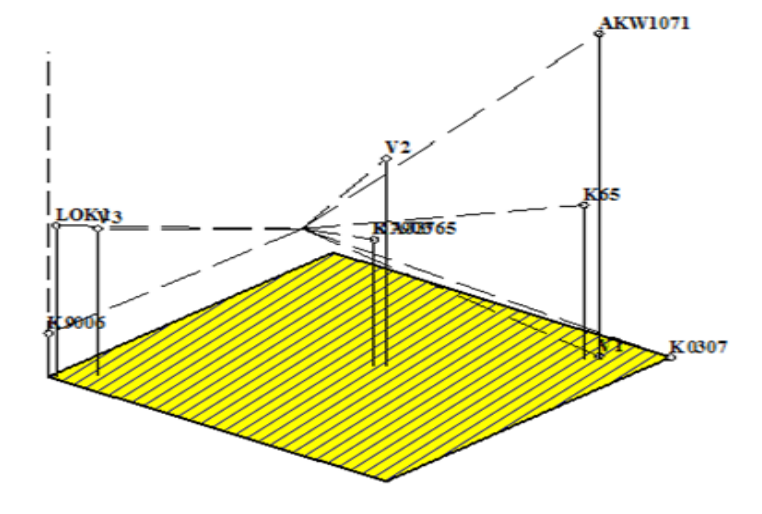

Fig. 3. Three-Dimensional structure of cultivars examined based on RAPD data.
19 followed by OPA 03 and OPA 08. In this experiment highest number of percent of polymorphism were detected in A01 (55\%) and minimum number of percent of polymorphism was detected in A16 (14.28\%).

The Similarity matrix based on possible pair of varieties ranged from 0.43 to 1.00 for hexaploid wheat cultivars. The minimum pair wise similarity $(0.43)$ was recorded between AKW 1071 and K9006 while maximum (1.00) pair wise similarity observed between Raj 3765 and K7903. The present investigation revealed that the high degree of genetic variability within the species.

The dendogram constructed on the basis of the similarity coefficient showed (Fig-1) that the cultivars of 

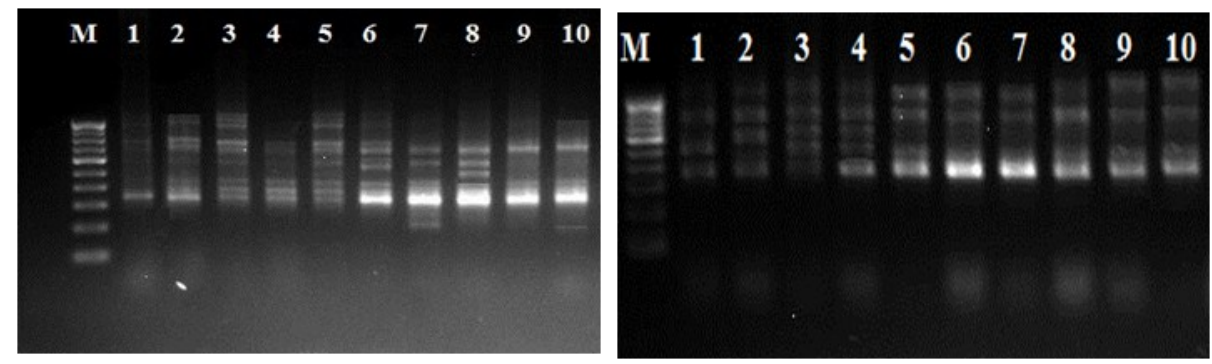

Fig. 4. RAPD amplified Product with 10 wheat cultivars using A01 and A16 Primers; M-Marker, 1-AKW1071, 2-K9006, K0307, K7903, RAJ 3765, Lok-1, V1,V2,V3 and K65.

wheat can be divided in to two main group AKW1071 was placed in $\mathrm{I}^{\text {st }}$ group and rest all nine varieties (K9006, Lok1, V3, Raj 3765, K-7903, K65, V2, $\mathrm{K} 0307$ and V1) were placed in $\mathrm{II}^{\text {nd }}$ group. II $^{\text {nd }}$ group can be further divided in to two sub groups. II A and II B. In II B K0307 and V1 are placed and rest seven varieties are placed in II A group. II A can be further divided into II $A_{1}$ and II $A_{2}$. In subgroup II $A_{1}$ has three varieties K9006, Lok 1 and V3 and Raj 3765, $\mathrm{K} 7903, \mathrm{~K} 65$ and V2 are placed in subgroup II $\mathrm{A}_{2}$. Two and three dimensional Structures (Fig-2 \& Fig-3) of 10 wheat cultivars examined which is based on molecular data. The present research work observed that the RAPD marker is valuable DNA marker for analysis of genetic diversity. Similar research works have been done by Siddiqui et al.,(2010), Farrakh et al., (2011) and Shabana Parveen et al., (2013). Grewal et al., (2007) observed that RAPD show maximum polymorphism among 20 Indian wheat cultivars.

\section{Conclusion}

It was concluded that the use of molecular marker such as RAPD has been verified for a considerable genetic diversity and genetic relationship between Indian wheat cultivars. The data obtained from this study confirmed that the efficiency of RAPD marker is high for the determination and estimation of genetic similarity among different wheat genotypes. In the present Investigation we observed that the high level of diversity seemed in 10 wheat cultivars. We found that the maximum genetic similarity occurs in K7903 and Raj 3765 while minimum genetic similarities were found in AK1071 and K9006. Finding in this study unraveled the efficiency of RAPD marker for assessment of genetic diversity, these marker would prove to be useful resource for wheat breeding. Finding in this study unraveled the efficiency of RAPD marker for assessment of genetic diversity. These RAPD markers would also be helpful in genomic mapping studies and for the development of wheat cultivars with diverse genetic background and to obtain improved crop productivity.

\section{ACKNOWLEDGEMENTS}

Authors are highly obliged to Dr. Rekha Dixit, Depart- ment of Biotechnology in the Keral Verma Faculty of Science, Swami Vivekanand Subharti University, Meerut for the encouragement and constructive suggestions.

\section{REFERENCES}

Ali, Ammar., Ali, Nawab, Ali, Imran., Adnan, Muhammad., Ullah, Nimat., Ahmed Zahoor (2013) Morphological and genetic diversity of Pakistani Wheat germplasm under drought stress. International Journal of Advancements in Research \& Technology.2(5):186-193.

Demeke, T., Laroche, A., Gaudet, D.A. (1996). A DNA marker for the Bt-10 common bunt resistance gene in wheat. Genome J. 39: 51-55.

Doyle, J. J. and Doyle, J. L. (1987) A rapid DNA isolationbprocedure for small quantities of fresh leaf tissue. Phyto. Bull.b19: 11-15.

Farrakh, S., Ahmad, Mirza, J. I., Hameed, S., Kazi, M., Ashraf, M. (2011) RAPD analysis of stripe rust resistant synthetic hexaploid of wheat. Int. J. Appl. Sci. Technol. $1: 3$.

Grewal, S., Kharb, P., Malik, R., Jain, S., Jain, R.K. (2007) Assessment of genetic diversity among some Indian wheat cultivars using random amplified polymorphic DNA (RAPD) markers. Indian J. Biotech. 6:18-33.

Hemrick, J.L., and Godt, M.J.W. (1990) Alloenzyme diversity in plant species, In: Plant Population Genetics, Breeding and Genetic Resources. (Eds.): A.H.D. Brown, M.T. Clegg, A.L. Kahler, B.S. Weir. Sinauer Associates Inc., Sunderland MA, pp. 43-63.

Jaccard, P. (1908) Nouvelles reserches sur la distribution florale. Bulletin Societe Vaudoise Des Sciences $\mathrm{Na}$ turelles. 44: 223-270.

Kumar, A., Singh, R., Singh, R., and Sengar, S. R. (2015). Molecular Approach for Detection of Plant pathogen. An International Journal of Biological Sciences Biotech today. 5(2):14 -19.

Kumar, S., Deepali, Mishra D. C., Bansal R., Kumari J., Kumar S. (2016) Molecular characterization of Indian wheat germplasm line for stay green $\&$ other heat tolerance genes using linked SSR markes. An International Jouranl of Biological Sciences Biotech today. 6(1):90 94.

Mahpara, S., Farooq, J., Ali, Z., Petrescu-Mag IV., Hussain, F. (2012) Assessment of genetic distance among wheat genotypes through RAPDmarkers. Advances in Agriculture and Botanics J. 4(1):31-35.

Nei, M., Li, W. H. (1979) Mathematical models for studying genetic variation in terms of restriction endonucleases. 
Proc. Natl. Acad. Sci. USA 76:5269-5273.

Parveen, S., Saharan, M.S., Verma., A and Sharma, I. (2013). Comparative analysis of RAPD and ISSR marker assays for detecting genetic polymorphism in Tilletia indica. European Journal of Experimental Biology 3 (1):380-387.

Siddiqui, M. F., Iqbal, S., Erum, S., Naz, Khan, S. (2010) DNA landmarks for genetic relatedness and diversity assessment in Pakistani wheat genotypes using RAPD markers. Pak. J. Bot. 42(2):1013-1020.
Sivolap, Y.M., Chebotar, S.V., Topchieva, E.A., Korzun,V. N., and Totskiy, V. N. (1999) RAPD and SSRP analyses of molecular-genetic polymorphism in Triticum aestivum L. cultivars. Russian J. Genet. 35: 14331440.

Tar'an, B., Zhang C., Warkentin T., Tullu, A., and Vandenberg (2005) A genetic diversity among varieties and wild species accessions of pea (Pisum sativum L.) based on molecular markers, and morphological and physiological characters. Genome, 48: 257-272. 